\title{
First estimates of volume distribution of HF-pump enhanced emissions at 6300 and $5577 \AA$ : a comparison between observations and theory
}

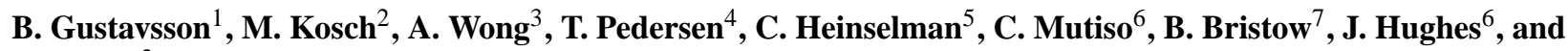 \\ W. Wang ${ }^{3}$ \\ ${ }^{1}$ Dept. of Physics and Technology, University of Troms $\varnothing$, Troms $\varnothing$, Norway \\ ${ }^{2}$ Department of Communication Systems, Lancaster University, Lancaster, UK \\ ${ }^{3}$ HIPAS Observatory, Two Rivers AK, USA \\ ${ }^{5}$ Space Vehicles Directorate, Air Force Research Laboratory, Hanscom AFB, MA, USA \\ ${ }^{4}$ SRI International, Menlo Park, CA, USA \\ ${ }^{6}$ Physical Science Dept, Embry-Riddle Aeronautical Univ., FL, USA \\ ${ }^{7}$ Geophysical Institute, University of Alaska, Fairbanks, AK, USA
}

Received: 20 December 2007 - Revised: 7 October 2008 - Accepted: 3 November 2008 - Published: 8 December 2008

\begin{abstract}
We present bi-static observations of radio-wave induced optical emissions at 6300 and $5577 \AA$ from a nighttime radio-induced optical emission ionospheric pumping experiment at the HIPAS (Fairbanks) facility in Alaska. The optical observations were made at HIPAS and from HAARP located $285 \mathrm{~km}$ south-east. From these observations the altitude distribution of the emissions is estimated with tomography-like methods. These estimates are compared with theoretical models. Other diagnostics used to support the theoretical calculations include the new Poker Flat AMISR UHF radar near HIPAS. We find that the altitude distribution of the emissions agree with electron transport modeling with a source of accelerated electrons located $20 \mathrm{~km}$ below the upper-hybrid altitude.
\end{abstract}

Keywords. Ionosphere (Active experiments; Ionosphereatmosphere interactions) - Radio science (Ionospheric physics)

\section{Introduction}

When a powerful HF radio wave is transmitted into the ionosphere with a frequency less than the peak ionospheric plasma frequency, this wave deposits most of its energy into the plasma in a narrow altitude region. This region ranges

Correspondence to: $\mathrm{B}$. Gustavsson

(bjorn.gustavsson@phys.uit.no) from the reflection altitude, where the pump frequency equals the local plasma frequency, $f_{P}$, down to the altitude of upper hybrid resonance, where the pump frequency, $f_{0}$, equals the local upper hybrid frequency, $f_{U H}=\left(f_{\gamma}^{2}+f_{P}^{2}\right)^{1 / 2}$, where $f_{\gamma}$ is the local electron gyro frequency, and at times kilometers lower. In addition to heating the electrons the HFpump wave drives plasma turbulence that leads to electron acceleration. The variation of electron and ion temperatures with time and altitude is well modeled with convection of heat and cooling by energy losses to ions and the neutral gas (e.g. Mantas et al., 1981; Carlson and Mantas, 1982). Direct observations of electrons accelerated by HF pumping is restricted to incoherent scatter radar observations of enhanced plasma lines (Carlson et al., 1982; Fejer and Sulzer, 1987), which showed HF-pump enhanced fluxes of electrons up to $20 \mathrm{eV}$. Observations of enhanced optical emissions indirectly show that HF-pumping increases the electron flux above the excitation thresholds of the emitting states. Therefore, observations of radio-induced optical emissions (RIOE) at $5577 \AA$ from $\mathrm{O}\left({ }^{1} \mathrm{~S}\right)$ (threshold $4.19 \mathrm{eV}$ ) (e.g. Bernhardt et al., 1989; Gustavsson et al., 2003), $6600 \AA$ from $\mathrm{N}_{2}\left(B^{3} \Pi_{g}\right)$ (threshold $7.35 \mathrm{eV})$ (Djuth et al., 1999), $7774 \AA$ from O $\left({ }^{3} \mathrm{p} 5 \mathrm{P}\right)$ (threshold $10.74 \mathrm{eV}$ ) (Djuth et al., 2005), $8446 \AA$ from $\mathrm{O}\left({ }^{3} \mathrm{p} 3 \mathrm{P}\right)$ (threshold $10.99 \mathrm{eV})$ (Gustavsson et al., 2005) and $4278 \AA$ from $\mathrm{N}_{2}^{+}$(threshold $18.75 \mathrm{eV}$ ) (Holma et al., 2006; Gustavsson et al., 2006), show that HF-radio waves accelerate electrons to suprathermal energies.

Published by Copernicus Publications on behalf of the European Geosciences Union. 

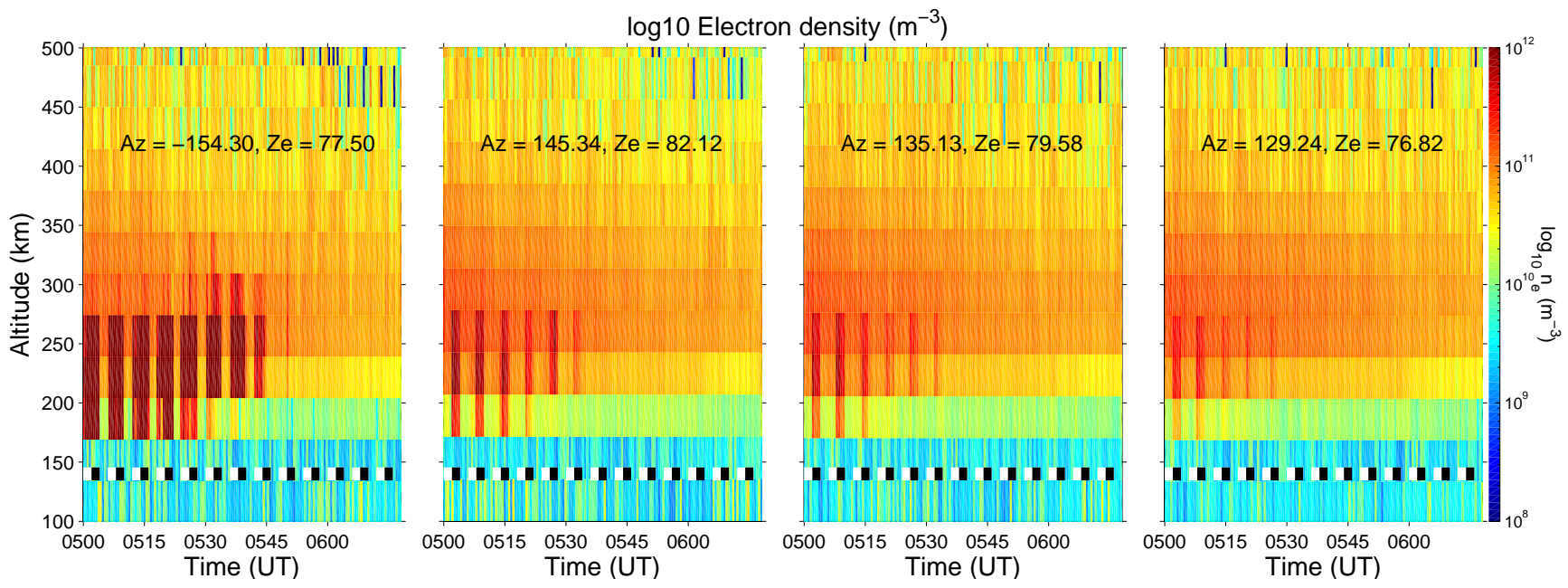

Fig. 1. The four panels shows the Poker Flat Incoherent Scatter Radar observations of electron densities in the 4 look directions. The white and black bars mark the pulsed and CW heating periods, respectively.

Bi-static optical observations showed that the RIOE are emitted from the F-region (Haslett and Megill, 1974; Adeishvili et al., 1978). The first multi-viewpoint observations of RIOE, with the Auroral Large Imaging System (Brändström, 2003), showed that the peak $6300 \AA$ enhancement is $5-15 \mathrm{~km}$ below the reflection altitude of the HF-wave (Brändström et al., 1999). This was corroborated by single viewpoint triangulation by Kosch et al. (2002). Under some conditions there is a descending of the RIOE from the start of the HF-pump pulses (Kosch et al., 2004; Ashrafi et al., 2007). Tomography-like retrieval of the $6300 \AA$ RIOE (Gustavsson et al., 2001) showed that the region of enhanced volume emission reached typical scale sizes of $20 \mathrm{~km}$, being slightly wider above than below the point of maximum volume emission rate. The combined knowledge of the altitude of the enhanced emission and the decay at $6300 \AA$ after HFoff give estimates of the $\mathrm{O}\left({ }^{1} \mathrm{D}\right)$ lifetime, $\tau_{\text {eff }}$, which is a function of the neutral density. Gustavsson et al. (2001) obtained $\tau_{\text {eff }}$ estimates at the altitudes of maximum volume emission rates, while Pedersen et al. (2008) obtained a profile over a larger range of altitudes by taking the decay at different altitudes.

Theoretical calculations of the altitude variation of the enhanced emissions have been made with a range of assumptions. Mantas and Carlson (1996) assumed that the enhanced emission was caused by excitation of thermal electrons, and used the bulk temperature observed with incoherent scatter (IS) radars to model the temporal evolution of column emission rates and altitude distribution of $6300 \AA \AA$ emissions. Bernhardt et al. (1989) used a point source of electrons accelerated up to $10 \mathrm{eV}$ to model the altitude distribution of the enhanced emissions at 6300 and $5577 \AA$. Bernhardt et al. (2000) assumed a supra-thermal Maxwellian electron distribution with a characteristic energy of $1.72 \mathrm{eV}$ - corresponding to a temperature of $19960 \mathrm{~K}$. Mishin et al. (2004) combined contributions to 6300 and $5577 \AA$ from electrons with thermal and power-law distributions to model the altitude distribution of the enhanced emissions. Gustavsson and Eliasson (2008) adjusted a parametrized acceleration term to calculate the altitude variation of electron flux from 1$100 \mathrm{eV}$ that reproduced observed column emission rates at $6300,5577,8446$ and $4278 \AA$. Altitude distributions of the emissions were an intermediate byproduct.

Here we will present the first estimates of threedimensional distributions of the enhanced emission from 6300 and $5577 \AA$ obtained from simultaneous observations from HIPAS $(64.87 \mathrm{~N}, 146.84 \mathrm{~W})$ and HAARP $(62.39 \mathrm{~N}$, $145.15 \mathrm{~W}$ ) during an HIPAS heating experiment on 19 March 2007. These estimates are then compared to theoretical model predictions.

\section{Experiment and data}

On 19 March 2007 HIPAS was operated in a 2 min on pulsed $50 \mathrm{~ms}$ every $250 \mathrm{~ms}, 2 \mathrm{~min} \mathrm{CW}, 2 \mathrm{~min}$ off transmitting sequence with $\approx 32 \mathrm{MW}$ effective radiated power at $2.85 \mathrm{MHz}$ $\left(f_{0}\right)$ pointing in the magnetic zenith from 04:24 to 06:58 UT using O-mode polarisation. During this time close to local sunset the ionospheric F-region electron density, $n_{e}$, decayed slowly as observed with the Poker Flat Incoherent Scatter Radar (PFISR, 65.13 ${ }^{\circ} \mathrm{N}, 147.47^{\circ} \mathrm{W}$ ), shown in Fig. 1. PFISR observed in four beams, one in the local magnetic zenith direction (77.5 elevation, $-154.3^{\circ}$ azimuth) and three beams intersecting the zenith over HIPAS at 200, 225 and $250 \mathrm{~km}$ of altitude. A map of the HIPAS/PFISR measurement geometry can be seen in Fig. 2. Unfortunately PFISR can not measure with beams cutting the magnetic field line through HIPAS. The large $n_{e}$ enhancements that appear in $4 \mathrm{~min}$ periods every $6 \mathrm{~min}$ in beam 1 and $2 \mathrm{~min}$ 
periods every $6 \mathrm{~min}$ in beams $2-4$ are due to enhanced ionlines caused by the HF-pump (e.g. Rietveld et al., 1993). For the ranges where this occurs the IS spectrum cannot accurately be analyzed to give electron densities and temperatures. However, for the period after 05:36 UT, when there is no enhanced ion line signature in beams $2-4$, and after 05:44 UT, when there is no enhanced ion line signature in beam 1 , the electron densities are accurately estimated. A detailed analysis of the pump modifications of electron temperatures as well as the details of the enhanced ion line signatures is outside the scope of this paper and will be addressed in a separate study. From 05:20 UT the twilight sky was dark enough to make the enhanced optical emissions observable at both 5577 ( $7 \mathrm{~s}$ exposures every $10 \mathrm{~s})$ and $6300 \AA$ ( $8 \mathrm{~s}$ exposures every $10 \mathrm{~s})$. Here we focus on the bi-static observations at the end of the CW HF pulses with start times from 05:32 to $05: 50 \mathrm{UT}$, when the background sky was dark enough to make the enhanced emission clearly separable above the background both from HIPAS and HAARP, as shown in Figs. 3 and 4, respectively. The imagers at HIPAS were pointing vertically with approximately $45^{\circ}$ field-of-view at 6300 and $75^{\circ}$ field-of-view at $5577 \AA$, whilst the HAARP imager was equipped with an all-sky optic and filter wheel.

\section{Data analysis}

To estimate the spatial distribution of the enhanced optical emissions we use a parametrized model for the excitation to the emitting state. For $I_{5577}$, that is emitted from $\mathrm{O}\left({ }^{1} \mathrm{~S}\right)$ with a radiative lifetime of approximately $0.7 \mathrm{~s}$, the volume emission rate is directly proportional to the excitation rate:

$$
I_{5577}(\boldsymbol{r})=A_{1 S} n_{\mathrm{O} 1 \mathrm{~S}}(\boldsymbol{r})=Q_{0} \exp \left\{-\sum_{i}\left|\frac{\Delta r_{i}}{\sigma_{i}}\right|^{\gamma}\right\}
$$

where $A_{1 S}=7.601 \times 10^{-2} \mathrm{~s}^{-1}$ is the Einstein coefficient for the transition from $\mathrm{O}\left({ }^{1} \mathrm{~S}\right)$ to $\mathrm{O}\left({ }^{3} \mathrm{P}_{1}\right)$. The parameters for the generalized Gaussian are: $Q_{0}$ - maximum excitation rate, $\sigma_{i}$ are the width in direction $i,(i=x, y, z)$, with $x$ east, $y$ north and $z \| \boldsymbol{B}$, and $\Delta r_{i}$ the distance away from the point of maximum excitation $r_{0 i}$ with $\Delta r_{i}=r_{i}-r_{0 i}$, and finally, $\gamma$ is a shape parameter. Here we use a two-sided Gaussian in altitude allowing for separate widths above, $\sigma_{z}^{u}$, and below, $\sigma_{z}^{d}, r_{0 z}$. This makes it possible to account for the variation in atmospheric density with altitude.

For $I_{6300}$, that is emitted from $\mathrm{O}\left({ }^{1} \mathrm{D}\right)$, which has a radiative lifetime of $107 \mathrm{~s}$ and an effective lifetime in the lower F-region varying with altitude due to the altitude variation of quenching, the volume emission rate is proportional to the $\mathrm{O}\left({ }^{1} \mathrm{D}\right)$ number density:

$I_{6300}(\boldsymbol{r})=A_{6300} n_{\mathrm{O} 1 \mathrm{D}}(\boldsymbol{r})$

where $A_{6300}=5.15 \times 10^{-3} \mathrm{~s}^{-1}$ is the Einstein coefficient for the transition from $\mathrm{O}\left({ }^{1} \mathrm{D}\right)$ to $\mathrm{O}\left({ }^{3} \mathrm{P}_{2}\right)$. Due to the long lifetime, we have to account for the effects of drift and diffusion

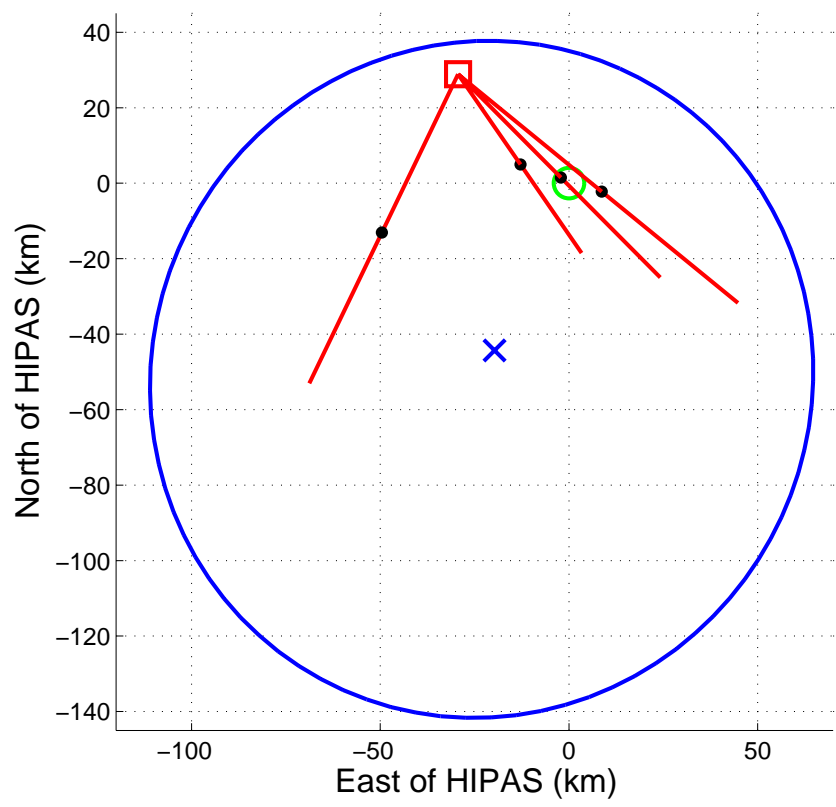

Fig. 2. A sketch showing the observational geometry from above. All positions are relative to the HIPAS site (marked with a green circle), the PFISR radar is located $29.3 \mathrm{~km}$ east and $28.7 \mathrm{~km}$ north of HIPAS, the direction of the four radar beams used are marked with red lines. The blue curve marks the $3 \mathrm{~dB}$ contour of the antenna pattern, the blue cross marks the magnetic field line position both at $210 \mathrm{~km}$ of altitude, and the black markers on the radar beams are their intersection with the $210 \mathrm{~km}$ altitude.

of $\mathrm{O}\left({ }^{1} \mathrm{D}\right)$ (Bernhardt et al., 2000). This we do by integrating a simplified $\mathrm{O}\left({ }^{1} \mathrm{D}\right)$ continuity equation for the $\mathrm{O}\left({ }^{1} \mathrm{D}\right)$ number density $n_{\mathrm{O} 1 \mathrm{D}}$ :

$\frac{\partial n_{\mathrm{O} 1 \mathrm{D}}}{\partial t}+\boldsymbol{v} \cdot \nabla n_{\mathrm{O} 1 \mathrm{D}}+D \nabla^{2} n_{\mathrm{O} 1 \mathrm{D}}=Q_{\mathrm{O} 1 \mathrm{D}}-\frac{n_{\mathrm{O} 1 \mathrm{D}}}{\tau_{\mathrm{eff}}}$

Where $v$ is the neutral wind, $D$ is the diffusion coefficient for $\mathrm{O}\left({ }^{1} \mathrm{D}\right)$, and $\tau_{\text {eff }}$ is the altitude dependent $\mathrm{O}\left({ }^{1} \mathrm{D}\right)$ effective lifetime,

$\frac{1}{\tau_{\mathrm{eff}}}=A_{6300}+A_{6364}+\sum n_{s} q_{s}$

The collisional de-excitation terms, $n_{s} q_{s}$, is calculated with the rate coefficients for quenching with $\mathrm{N}_{2}$ of $q_{1}=2.0 \times 10^{-11} \exp \left(107.8 / T_{n}\right) \mathrm{cm}^{3} \mathrm{~s}^{-1}$, with $\mathrm{O}_{2}$ of $q_{2}=2.9 \times 10^{-11} \exp \left(67.5 / T_{n}\right) \mathrm{cm}^{3} \mathrm{~s}^{-1}$ (Mantas and Carlson, 1996), and with atomic oxygen: $q_{3}=2.0 \times 10^{-12} \mathrm{~cm}^{3} \mathrm{~s}^{-1}$ (Solomon et al., 1988). Here we calculate $\sum n_{s} q_{s}$ using the MSIS model atmosphere (Hedin, 1991) for the HIPAS location, shown in Fig. 5.

For the $\mathrm{O}\left({ }^{1} \mathrm{D}\right)$ excitation rate $Q_{\mathrm{O} 1 \mathrm{D}}$ we use a generalized Gaussian:

$Q_{\mathrm{O} 1 \mathrm{D}}(\boldsymbol{r})=Q_{0} \exp \left\{-\sum_{i}\left|\frac{\Delta r_{i}}{\sigma_{i}}\right|^{\gamma}\right\}$ 


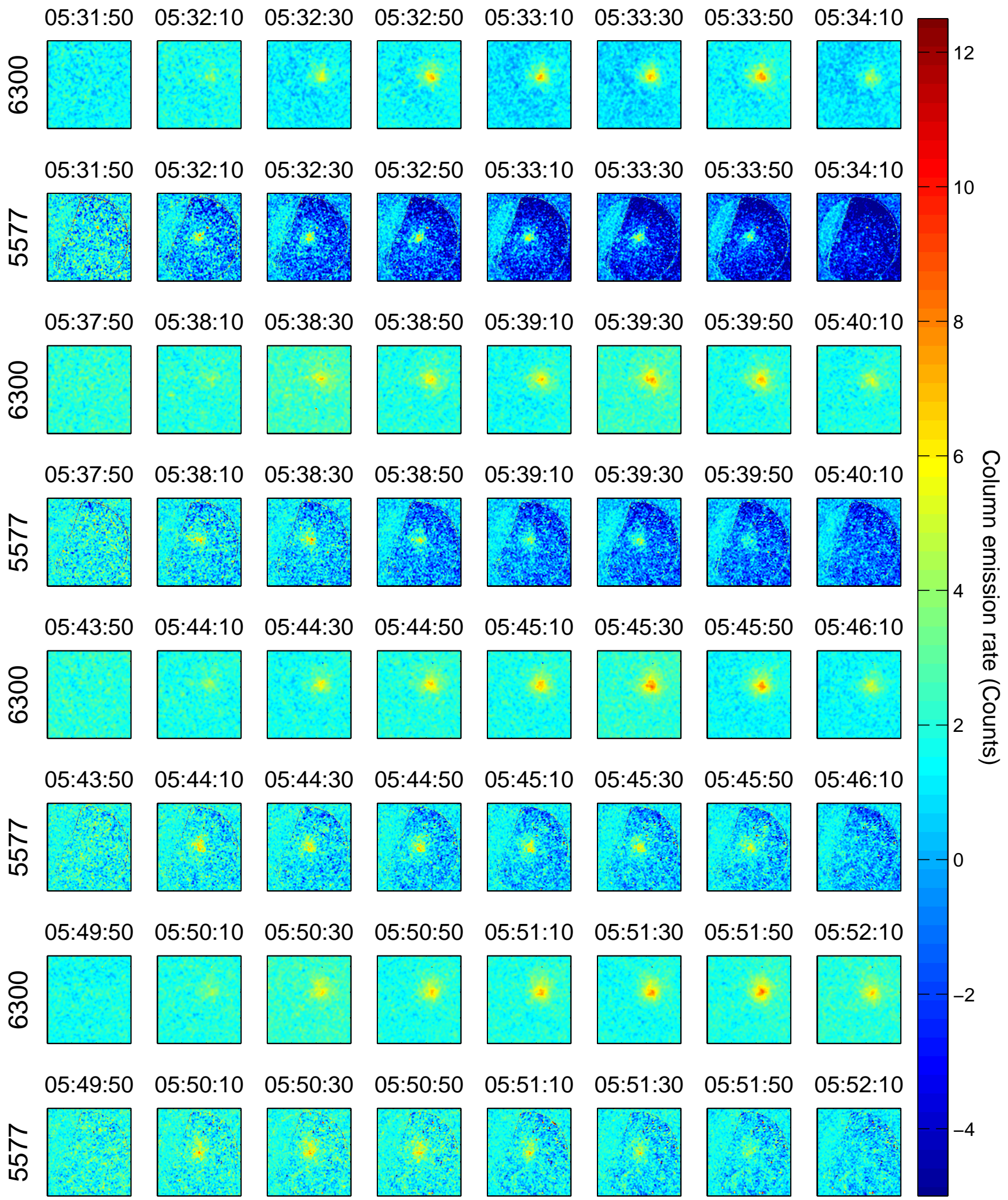

Fig. 3. Wide field-of-view $\left(\approx 45^{\circ}\right.$ at $6300 \AA, \approx 75^{\circ}$ at $\left.5577 \AA\right)$ optical observations from the HIPAS site show the gradual increase and decay of the enhanced emissions at $6300 \AA$ and the instantaneous on-off characteristics (at the $7 \mathrm{~s}$ exposure $10 \mathrm{~s}$ inter-exposure time of the observations) at $5577 \AA$. Both emissions are presented in relative units. Time increments are $20 \mathrm{~s}$ steps. 

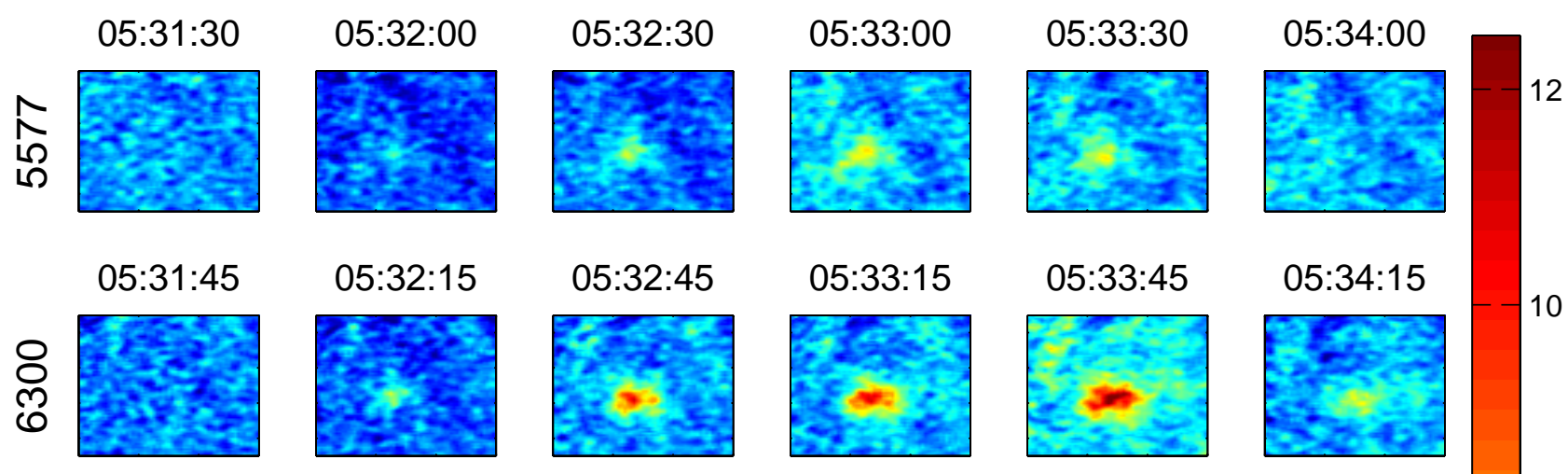

10
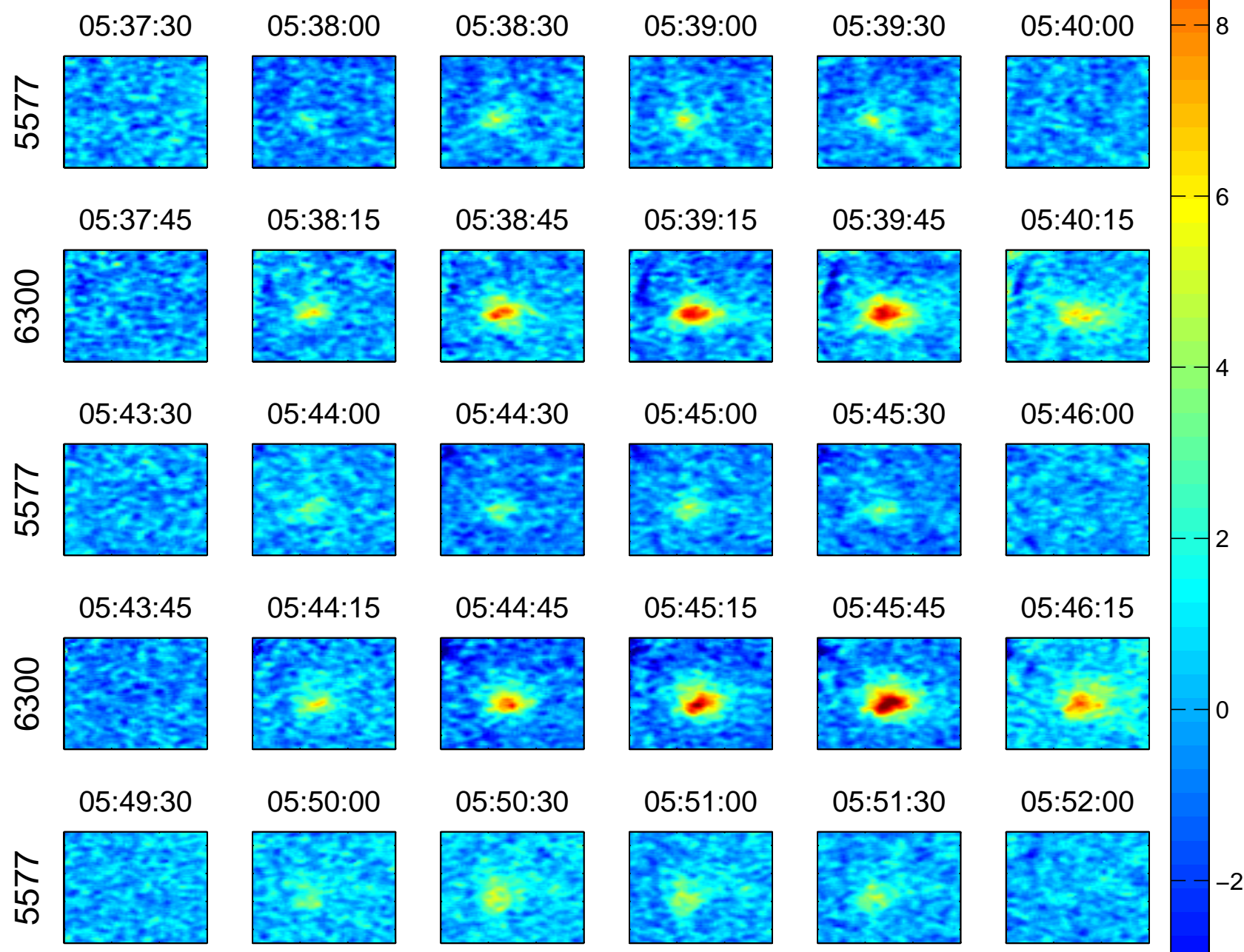

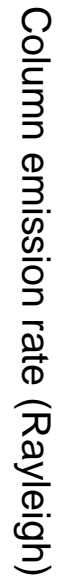
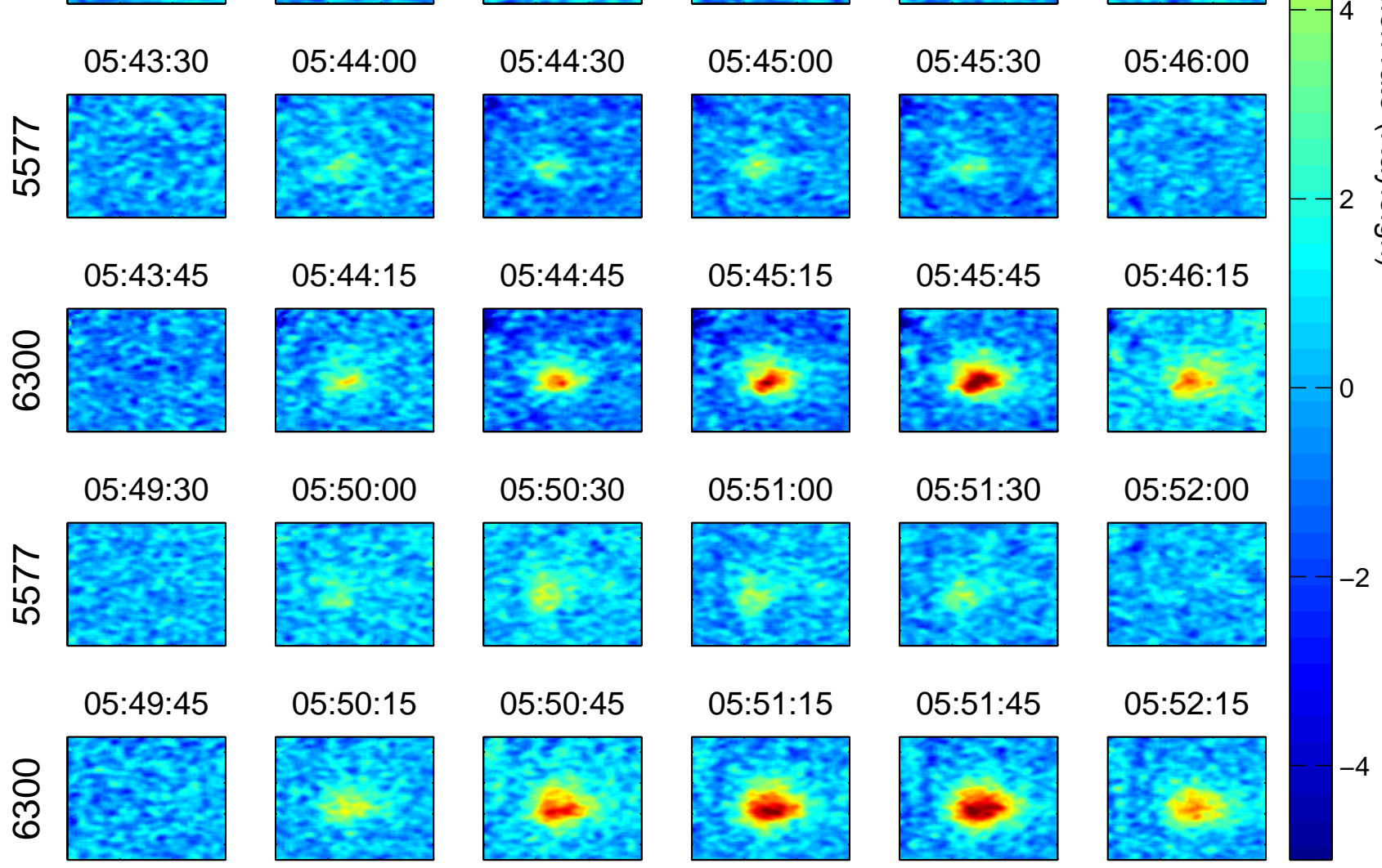

Fig. 4. The all-sky imager at the HAARP site was operated at a $15 \mathrm{~s}$ cadence switching filters between 6300 and $5577 \AA$ between exposures. Here we show a close-up region that approximately covers azimuth angles from $-10^{\circ}$ from north to $-50^{\circ}$, and elevations between $20^{\circ}$ and $60^{\circ}$, the $6300 \AA$ blob covers approximately $10^{\circ}$ by $10^{\circ}$. 

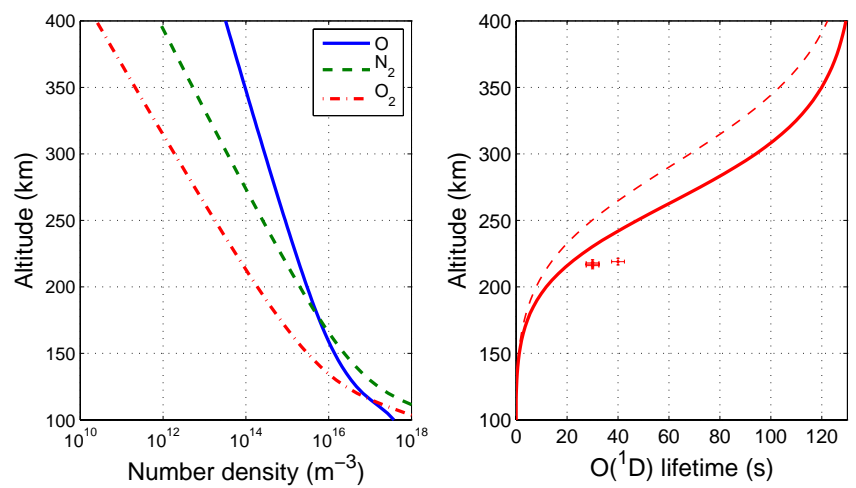

Fig. 5. In the left panel is the MSIS model atmosphere (Hedin, 1991) for HIPAS on 19 March 2007, and in the right panel is the estimate of the altitude variation of $\mathrm{O}\left({ }^{1} \mathrm{D}\right)$ effective lifetime, calculated with the $\mathrm{O}\left({ }^{1} \mathrm{D}\right)+\mathrm{O}\left({ }^{3} \mathrm{p} 3 \mathrm{P}\right)$ quenching rate of $2 \times 10^{-18} \mathrm{~cm}^{3} \mathrm{~s}^{-1}$ from Solomon et al. (1988) (thick solid curve) and with the $22 \times 10^{-18} \mathrm{~cm}^{3} \mathrm{~s}^{-1}$ from Closser et al. (2005) (thin dashed curve). The red points with horizontal and vertical error bars mark the $\mathrm{O}\left({ }^{1} \mathrm{D}\right)$ lifetime estimated from the decay of the HIPAS observations at 6300 at the altitude of the emission, as discussed in Sect. 4.

This makes it possible to include additional free parameters for horizontal wind, $v_{x}, v_{y}$, and diffusion, $D$. With these free parameters it is possible to account for $\mathrm{O}\left({ }^{1} \mathrm{D}\right)$ widening and drifting away from the excitation region with the neutral wind, which would give the $I_{6300}$ a comet-like tail in the wind direction. Here we assume that the parameters are constant with time. This is unproblematic for $I_{5577}$ since $\mathrm{O}\left({ }^{1} \mathrm{~S}\right)$ has a sufficiently short lifetime and the optical data cannot resolve variations on that timescale. For $I_{6300}$ where the $\mathrm{O}\left({ }^{1} \mathrm{D}\right)$ lifetime is longer than the interval between exposures, it is possible to estimate the temporal evolution of the volume emission rates, as was done in Gustavsson et al. (2001). Since the focus here is on the relation between the enhanced volume emission rates at 5577 and $6300 \AA$ during steady state, we assume $\bar{p}_{6300}$, defined below, to be constant over time as well.

To estimate the volume emission rates we search for the respective set of free parameters $\bar{p}_{5577}=\left[Q_{0}, r_{x 0}, r_{y 0}, r_{z 0}\right.$, $\left.\sigma_{x}, \sigma_{y}, \sigma_{z}^{u}, \sigma_{z}^{d}, \gamma\right]$ and $\bar{p}_{6300}=\left[Q_{0}, r_{x 0}, r_{y 0}, r_{z 0}, \sigma_{x}, \sigma_{y}, \sigma_{z}^{u}\right.$, $\left.\sigma_{z}^{d}, \gamma, v_{x}, v_{y}, D\right]$ that minimize the total least squares error

$\min \sum_{s, u, v}\left(P_{S}(u, v)-\tilde{P}_{s}\left(u, v, I_{\lambda}\left(\boldsymbol{r}, \bar{p}_{\lambda}\right)\right)\right)^{2}$

where $P_{S}(u, v)$ is the observed intensity within pixel $(u, v)$ after background subtraction, in the image taken at station $s$ and $\tilde{P}_{s}\left(u, v, I\left(\boldsymbol{r}, \bar{p}_{\lambda}\right)\right)$ is the corresponding image intensity calculated from the modeled three-dimensional airglow $I_{\lambda}\left(\boldsymbol{r}, \bar{p}_{\lambda}\right)$. Minimization of Eq. (6) for $5577 \AA$ A observations at 05:33:00, 05:39:00, 05:45:00 and 05:51:00 UT, and for $6300 \AA$ observations at $05: 33: 45,05: 39: 45,05: 45: 45$ and 05:51:45 UT, all produce good fits between observed images
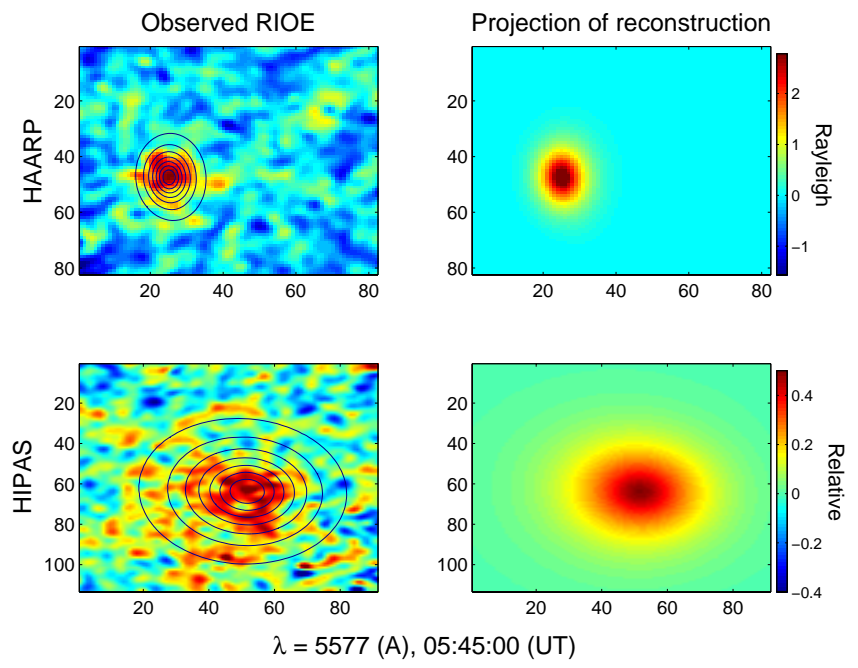

Fig. 6. This figure shows the image regions with the enhanced emissions at $5577 \AA$. In the top row left panel the observed HAARP image is overlaid with contour lines from the projection of the modeled emissions, from Eq. (1), with the optimal parameters from Eq. (6). The top right panel displays the projection of the modeled image as seen from the HAARP site. The bottom left panel shows the observed image from HIPAS, overlaid with contours of the projection of the modeled emission. The bottom right panel shows the projection of the modeled emission as seen from HIPAS.
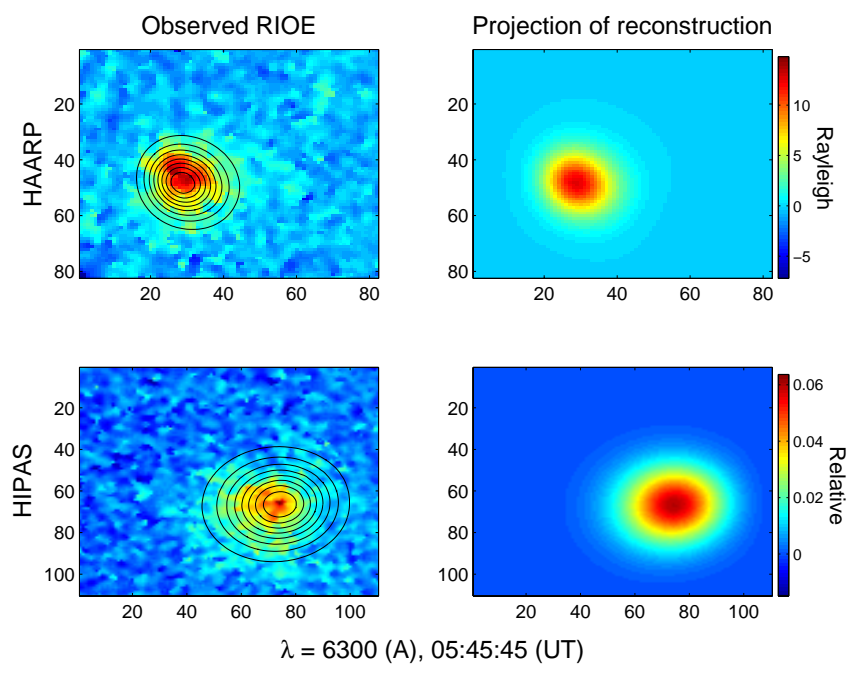

Fig. 7. Here we show the fit between observations and the optimal model for $6300 \AA$. The panels are organized identically with Fig. 6 .

and projections of the modeled emissions, as can be seen in Figs. 6 and 7.

\section{Results and comparison with theory}

The estimated three-dimensional distributions of enhanced volume emission rates show that the horizontal and vertical widths of 6300 is wider with a broader peak than $5577 \AA$, as 


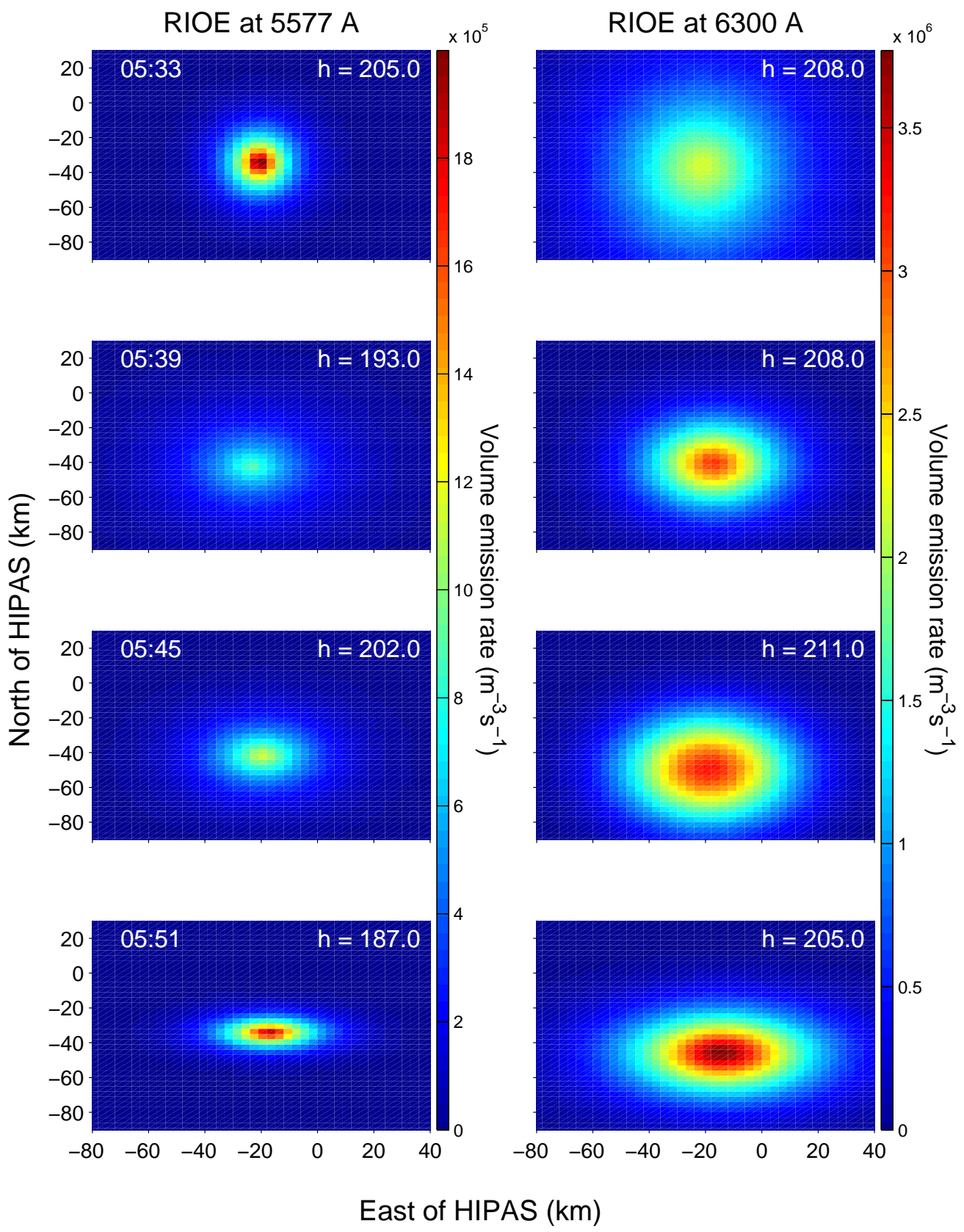

Fig. 8. The left and right panels show the horizontal cuts through the maximum of the enhanced volume emission at 5577 and $6300 \AA$, respectively, at the altitudes marked. Note that the region of enhanced volume emission rates are spatially wider with a broader peak at $6300 \AA$.

can be seen in Fig. 8. To some extent this can be explained by diffusion causing a relatively larger widening of $n_{\mathrm{O} 1 \mathrm{D}}$ than $n_{\mathrm{O} 1 \mathrm{~S}}$ but we also find that the width of $\mathrm{O}\left({ }^{1} \mathrm{D}\right)$ excitation is typically $12-14 \mathrm{~km}$ wider. Here we calculate the width, $\sigma_{\lambda}$ as

$\sigma_{\lambda}^{2}=\int I(r)\left(\boldsymbol{r}_{\mathrm{coe}}-\boldsymbol{r}\right)^{2} d V / \int I(\boldsymbol{r}) d V$, which corresponds to the $1 / e$ half-width for a Gaussian, around the center of emission $\bar{r}_{\mathrm{coe}}$

$r_{\mathrm{coe}}=\int I(\boldsymbol{r}) \boldsymbol{r} d V / \int I(\boldsymbol{r}) d V$

This finding differs from the results of Gustavsson et al. (2003) where it was found that the $I_{5577} / I_{6300}$ ratio was constant over the entire enhanced region. Whether the reason for this discrepancy is due to the different HF-pump 


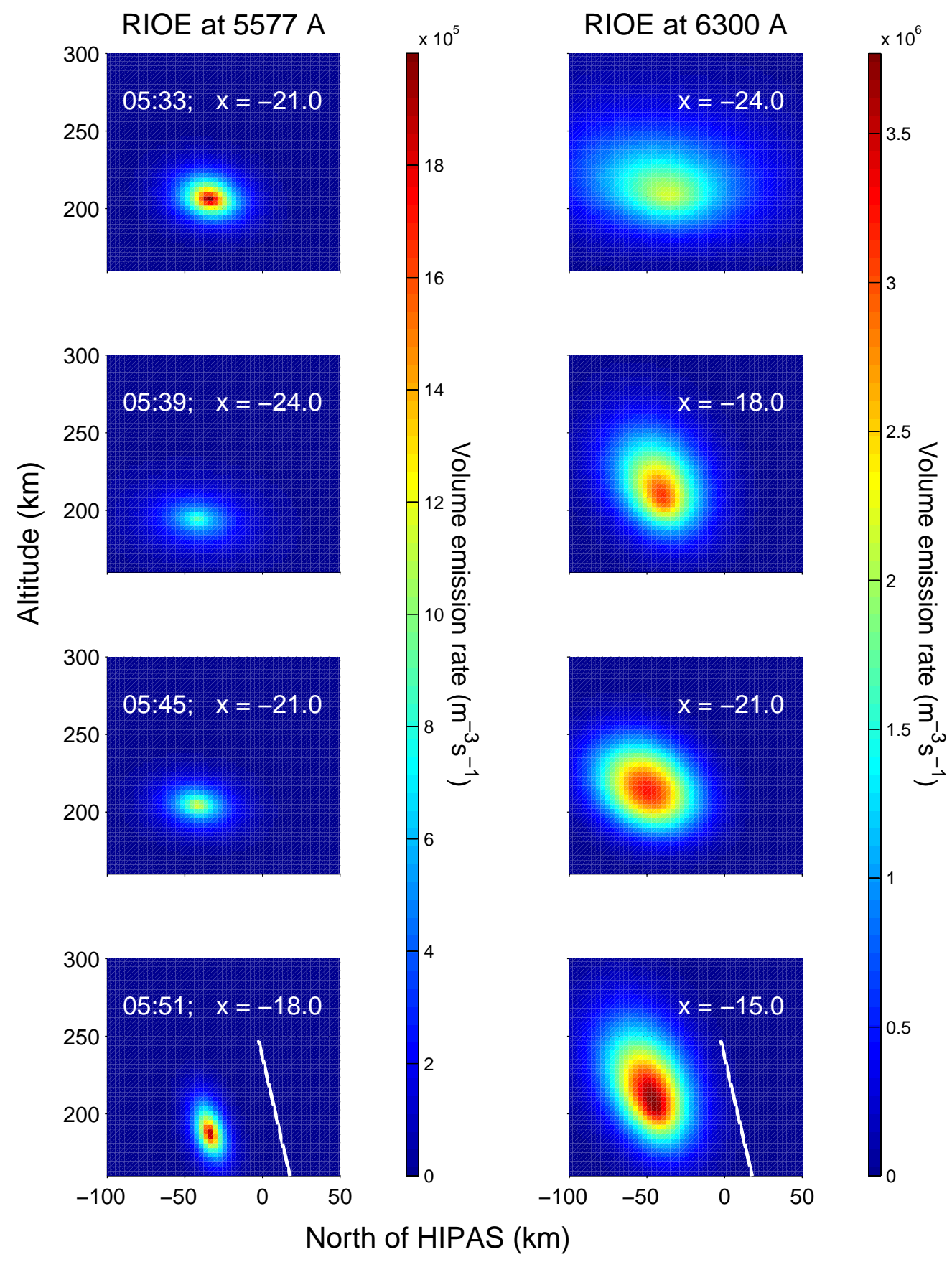

Fig. 9. The left and right panels show the vertical meridional cuts through the maximum of the enhanced volume emission at 5577 and $6300 \AA$, respectively, at the positions and times shown. Note that the region of enhanced volume emission rates extends to higher altitudes at $6300 \AA$. The white lines show the inclination of the magnetic field.

frequencies used (2.85 and $4.04 \mathrm{MHz})$ or the different ERP (32 and $125 \mathrm{MW}$ ) requires further experiments to clarify.

The estimated shape of the enhanced emissions varies from being slightly flat to more elongated along the magnetic field line. The small southward tilt off the magnetic inclination seen for the $6300 \AA$ emission in Fig. 9 is caused by $\mathrm{O}\left({ }^{1} \mathrm{D}\right)$ drifting with the neutral wind, an effect making a larger impact at higher altitudes where $\tau_{\text {eff }}$ is longer. Our estimate of the neutral wind is approximately $300 \mathrm{~m} / \mathrm{s}$ with a slightly varying direction around westward. These estimates of the neutral wind agrees reasonably well with winds from the Coupled Thermosphere-Ionosphere- Plasmasphere (CTIP) (Fuller-Rowell et al., 1996; Millward et al., 1996) model calculations, that show westward winds between 160 


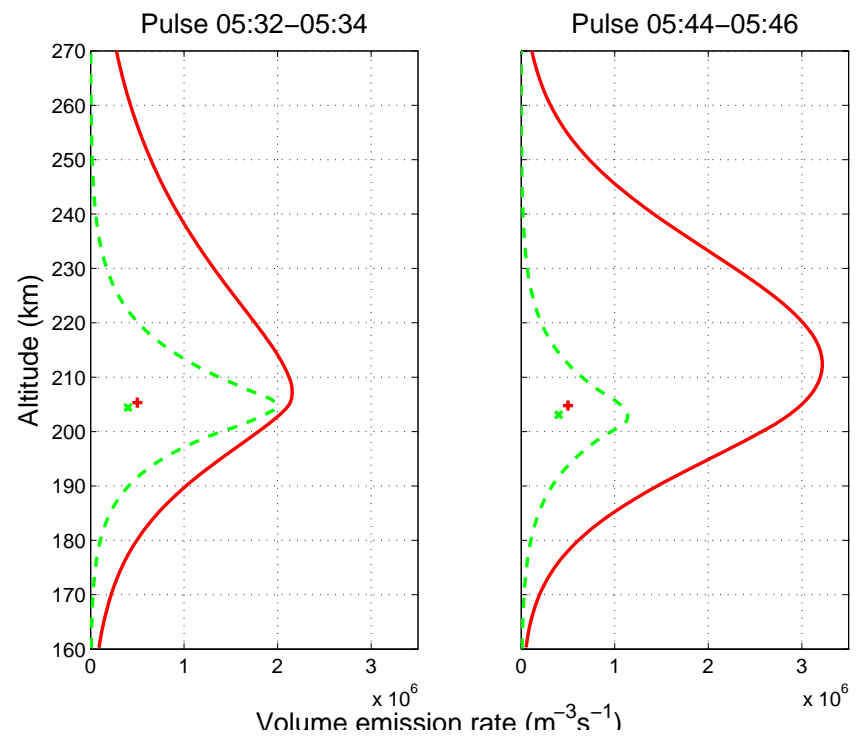

Fig. 10. The altitude variation of the enhanced emissions agrees well with the theoretical calculations (e.g. Bernhardt et al., 2000; Gustavsson and Eliasson, 2008) with center of emission a few kilometer above the center of excitation for $5577 \AA$ (dashed green curve) and $\sim 15 \mathrm{~km}$ for $6300 \AA$ (solid red curve). Further, the width in altitude is $7-15 \mathrm{~km}$ wider for 6300 than $5577 \AA$. The centers of excitation are shown as $+(6300 \AA)$ and $\mathrm{x}(5577 \AA)$.

and $180 \mathrm{~m} / \mathrm{s}$ and southward winds between 50 and $70 \mathrm{~m} / \mathrm{s}$. The altitude variation of $I_{5577}$ is narrower and more peaked than $I_{6300}$. For the two pulses shown in Fig. 10 the excitation sources were found to be co-located. For the other two pulses the $\mathrm{O}\left({ }^{1} \mathrm{~S}\right)$ source were found to be centered approximately $10 \mathrm{~km}$ lower. The altitude of the excitation centers, the center-of-emission as well as the widths in altitude of the emissions are listed in Table 1 . The $6300 \AA$ center of emission is typically $10-15 \mathrm{~km}$ above the $\mathrm{O}\left({ }^{1} \mathrm{D}\right)$ excitation, while the 5577 center-of-emission is not more than $3 \mathrm{~km}$ above the $\mathrm{O}\left({ }^{1} \mathrm{~S}\right)$ excitation. The main reason for the upward shift of the $6300 \AA$ emission is the large relative increase of $\tau_{\text {eff }}$ with altitude, as can be seen in Fig. 5 . While the small shift of the $5577 \AA$ emission is due to the increasing electron mean free path with altitude. The shape of the altitude variation agrees with theoretical modeling (Bernhardt et al., 2000; Gustavsson and Eliasson, 2008) based on electron transport with $I_{5577}$ narrower and $I_{6300}$ wider mainly towards higher altitudes. The accuracy of the center-of-emissions is approximately $\pm 3 \mathrm{~km}$, the error calculations and sensitivities to noise is discussed in Appendix A.

The PFISR IS radar observations indicate that for the last two pulses and perhaps also the pulse of 05:38-05:40 (UT) $f_{O} \mathrm{~F}_{2}$ was below $f_{0}$, see Table 2 . This rules out direct HF-pump driven Langmuir turbulence (LT) as the mechanism accelerating the electrons, since LT requires $f_{0}<f_{O} \mathrm{~F}_{2}$. Since $f_{0}<f_{U H} \mathrm{~F}_{2}$ upper-hybrid waves can still be excited which can cause electron acceleration (Mishin et al., 2004;
Table 1. Table 1 Altitude of excitation and emission, as estimated. Here $\mathrm{O}\left({ }^{1} \mathrm{D}\right)$ and $\mathrm{O}\left({ }^{1} \mathrm{~S}\right)$ denotes excitation of respective state, for which we list the center-altitude of the generalized Gaussian, and "coe R/G" denotes center of emission for the volume emission rates at 6300 and $5577 \AA$ respectively. Characteristics of volume emission estimates.

\begin{tabular}{ccccccc}
\hline $\begin{array}{c}\text { Pulse } \\
(\mathrm{UT})\end{array}$ & $\mathrm{O}\left({ }^{1} \mathrm{D}\right)$ & altitude $(\mathrm{km})$ & \multicolumn{3}{c}{ width $(\mathrm{km})$} \\
\hline $05: 33$ & 205 & 219 & 204 & 206 & 27 & 12 \\
$05: 39$ & 203 & 217 & 193 & 194 & 24 & 15 \\
$05: 45$ & 205 & 216 & 203 & 203 & 20 & 12 \\
$05: 51$ & 201 & 218 & 186 & 189 & 27 & 14 \\
\hline
\end{tabular}

Table 2. Table 2 show the most HF-pump-relevant ionospheric parameters. Here we have calculated $f_{O} \mathrm{~F}_{2}$ and $f_{U H} \mathrm{~F}_{2}$ as the highest plasma and upper-hybrid frequency in all four PFISR beams. Ionospheric parameters.

\begin{tabular}{ccccc}
\hline $\begin{array}{c}\text { Pulse } \\
(\mathrm{UT})\end{array}$ & $\begin{array}{c}f_{O} \mathrm{~F}_{2} \\
(\mathrm{MHz})\end{array}$ & $\begin{array}{c}f_{U H} \mathrm{~F}_{2} \\
(\mathrm{MHz})\end{array}$ & $\begin{array}{c}h\left(f_{0}=f_{U H}\right) \\
(\mathrm{km})\end{array}$ & $\begin{array}{c}\Delta f \\
(\mathrm{kHz})\end{array}$ \\
\hline 05:29:00 & 2.90 & 3.24 & 224 & -35 \\
$05: 35: 00$ & 3.21 & 3.50 & 225 & -33 \\
$05: 41: 00$ & 2.77 & 3.12 & 223 & -25 \\
$05: 47: 00$ & 2.79 & 3.14 & 232 & -33 \\
$05: 53: 00$ & 2.70 & 3.05 & 221 & -5 \\
\hline
\end{tabular}

Mishin et al., 2005; Kosch et al., 2007a, and references therein). However, the altitude difference between the excitation found from the optical observations and the upper hybrid altitude is unaccounted for. This downward shift might be caused by focusing of the reflected waves from an HFmodified reflection layer forming a concave mirror as suggested by Kosch et al. (2007b). Reflected waves would then focus leading to large enhancement of the total electrical field at an altitude below the reflection layer. Reflection from such concave structures, produced by chemical release, have been observed in-situ (Bernhardt et al., 1995), and there is also some theoretical support indicating that HF-transmission can create such density modifications (Gondarenko et al., 2005). It is also worth noting that the center of excitation is at the altitude where the $\mathrm{X}$-mode/right-hand polarisation cut-off frequency $\left(f_{R}=1 / 2\left[f_{e}+\left(f_{e}^{2}+4 f_{p}^{2}\right)^{1 / 2}\right]\right)$ equals $f_{0}$.

With knowledge of the altitude distribution of the $6300 \AA$ volume emission rate and the $10 \mathrm{~s}$ cadence image observations of the decay from the HIPAS site it is possible to compare the observed decay rate with theoretical estimates. It has been shown (Gustavsson et al., 2001) that the altitude averaged $O\left({ }^{1} \mathrm{D}\right)$ lifetime (e.g. Bernhardt et al., 2000) agrees to within $\pm 2 \mathrm{~s}$ with the lifetime at the altitude of maximum emission rate. In Fig. 11 the total enhanced emissions at 6300 (and 5577) $\AA$ are plotted, using HIPAS optical data, with the 

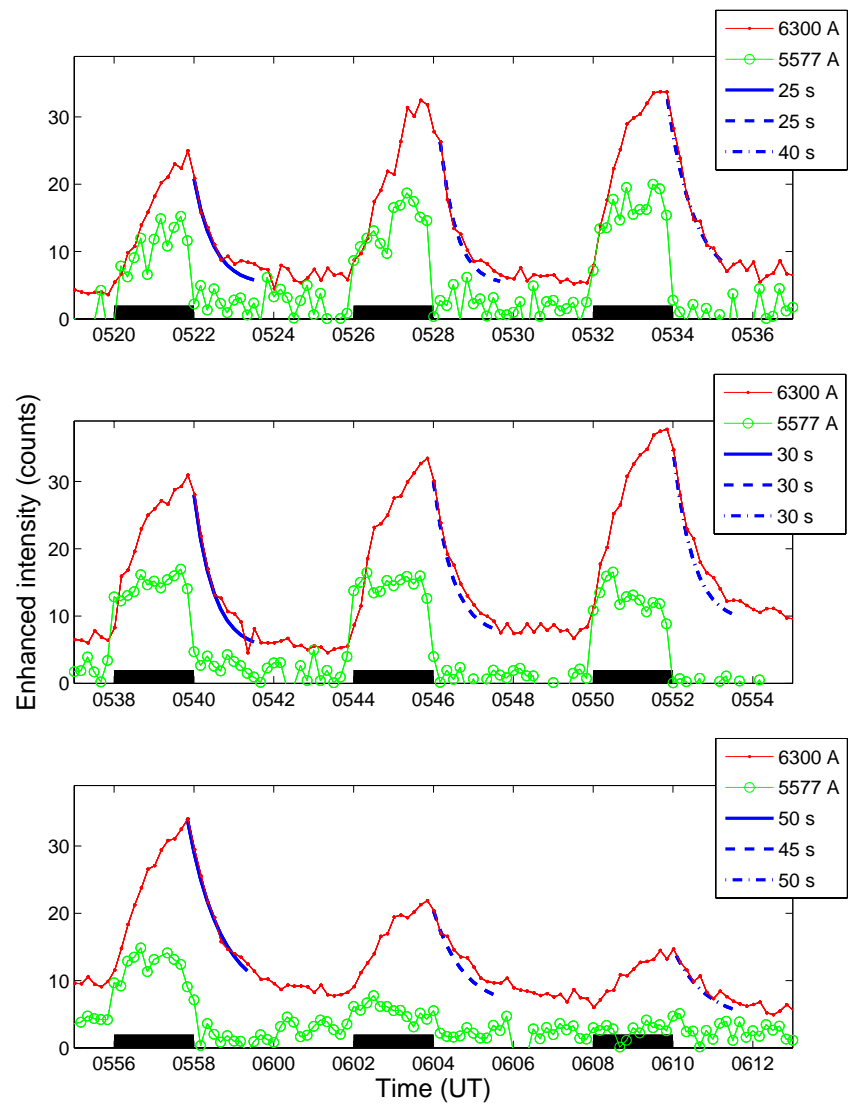

Fig. 11. The three panels display the average enhanced intensity at $5577 \AA$ (green curve with o markers) and at $6300 \AA$ (red curve with dot markers) together with the best fit decay curves for each pulse (blue curves). The black bar marks the 2 min period of $\mathrm{CW}$ heating.

best fitting decay-curves. Here it is necessary to note that although the standard deviation for individual pixel intensities is large, $\tau_{\text {eff }}$ is calculated from the average intensity of the entire blob, thus the corresponding standard deviation is approximately 2 counts or only about $5 \%$ of the total intensity. This leads to the estimate of the decay time uncertainty to be no worse than $\pm 3 \mathrm{~s}$.

When comparing the 30 and $40 \mathrm{~s}$ e-folding times for the 05:32-05:50 UT pulses with the theoretical altitude variation of $\tau_{\text {eff }}$ in Fig. 5, we see that at the altitude of maximum emission the expected lifetime is only approximately $20 \mathrm{~s}$ at $215 \mathrm{~km}$ altitude compared to the 30 and $40 \mathrm{~s}$ observed.

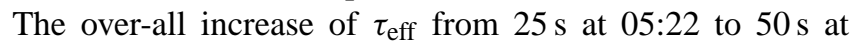
06:10 UT can be explained by the rise of the upper-hybrid altitude from approximately $200 \mathrm{~km}$ to $260 \mathrm{~km}$ between 05:20 and 06:10 UT, while $\tau_{\text {eff }}$ for each individual pulse can be affected by transport due to vertical winds, that at times are variable even on short time-scales (e.g. Aruliah et al., 2005).

This estimate is done with the rate coefficients for quenching with $\mathrm{N}_{2}$ of $q_{1}=2.0 \times 10^{-11} \exp \left(107.8 / T_{n}\right) \mathrm{cm}^{3} \mathrm{~s}^{-1}$, with $\mathrm{O}_{2}$ of $q_{2}=2.9 \times 10^{-11} \exp \left(67.5 / T_{n}\right) \mathrm{cm}^{3} \mathrm{~s}^{-1}$ (Man- tas and Carlson, 1996), and with atomic oxygen: $q_{3}=2.0 \times 10^{-12} \mathrm{~cm}^{3} \mathrm{~s}^{-1}$ (Solomon et al., 1988). With recent laboratory experiments showing a ten times higher $\mathrm{O}\left({ }^{1} \mathrm{D}\right)$ quenching rate with $\mathrm{O}\left({ }^{3} \mathrm{p} 3 \mathrm{P}\right)$ (Closser et al., 2005; Kalogerakis et al., 2006) the effective lifetime would be further reduced by $5-25 \mathrm{~s}$ for 200 to $280 \mathrm{~km}$ of altitude. To make the theoretical $\tau_{\text {eff }}$ fit with our observations the neutral densities would have to be reduced from the MSIS prediction by $50 \%$ with the quenching rates of Solomon et al. (1988), or with $67 \%$ with the quenching rates of Closser et al. (2005).

On this point further experiments are needed to investigate this quenching rate, that are most important in controlling the energy flow in the upper atmosphere. Preferably, HF-pump experiments would be combined with in-situ observations of the neutral densities. In this way it would be possible to remove the uncertainty in the neutral atmosphere, which can have a day to day variability of factor 3 or more (e.g. Killeen and Roble, 1988; Hecht et al., 2006).

\section{Summary and conclusion}

In this report we have used bi-static optical data at 6300 and $5577 \AA$ to estimate the three-dimensional distribution of their volume emission rates. The center of excitation we find is approximately $20 \mathrm{~km}$ below the upper-hybrid altitude as estimated from the PFISR electron density measurements, this might be explained by focusing of the HF-beam by a HFmodified reflection layer acting as a concave mirror. We find that the volume emission rate at $6300 \AA$ is wider and has a broader altitude peak. Further, we find that the altitude variation of the enhanced emissions agree, within the measurement uncertainty, with previous modeling predictions. The decay of the observed $6300 \AA$ indicates that either the current estimates of the $\mathrm{O}\left({ }^{1} \mathrm{D}\right)$ quenching rates with $\mathrm{N}_{2}$ and $\mathrm{O}(3 \mathrm{P})$ are too large or the neutral densities were a factor of two lower than the MSIS model predicts. To clarify this requires new experiments, preferably simultaneous in situ observation of neutral densities during HF-heating experiments. However, since $\mathrm{O}\left({ }^{1} \mathrm{D}\right)$ effective life-times that are longer than predicted seems to be found systematically (Gustavsson et al., 2001; Pedersen et al., 2008), this also calls out for improvemed measurements of quenching rates. From the skewness of the $6300 \AA$ volume emission rates we obtain estimates of the neutral wind that agrees reasonably well with winds from the CTIP model calculations.

\section{Appendix A}

\section{Geometric camera calibration and error analysis}

To make a first-order of magnitude estimate of the accuracy of the altitude estimates we shift the distribution of volume emission up and down. When doing this systematic patterns in the residuals between the observed images from 

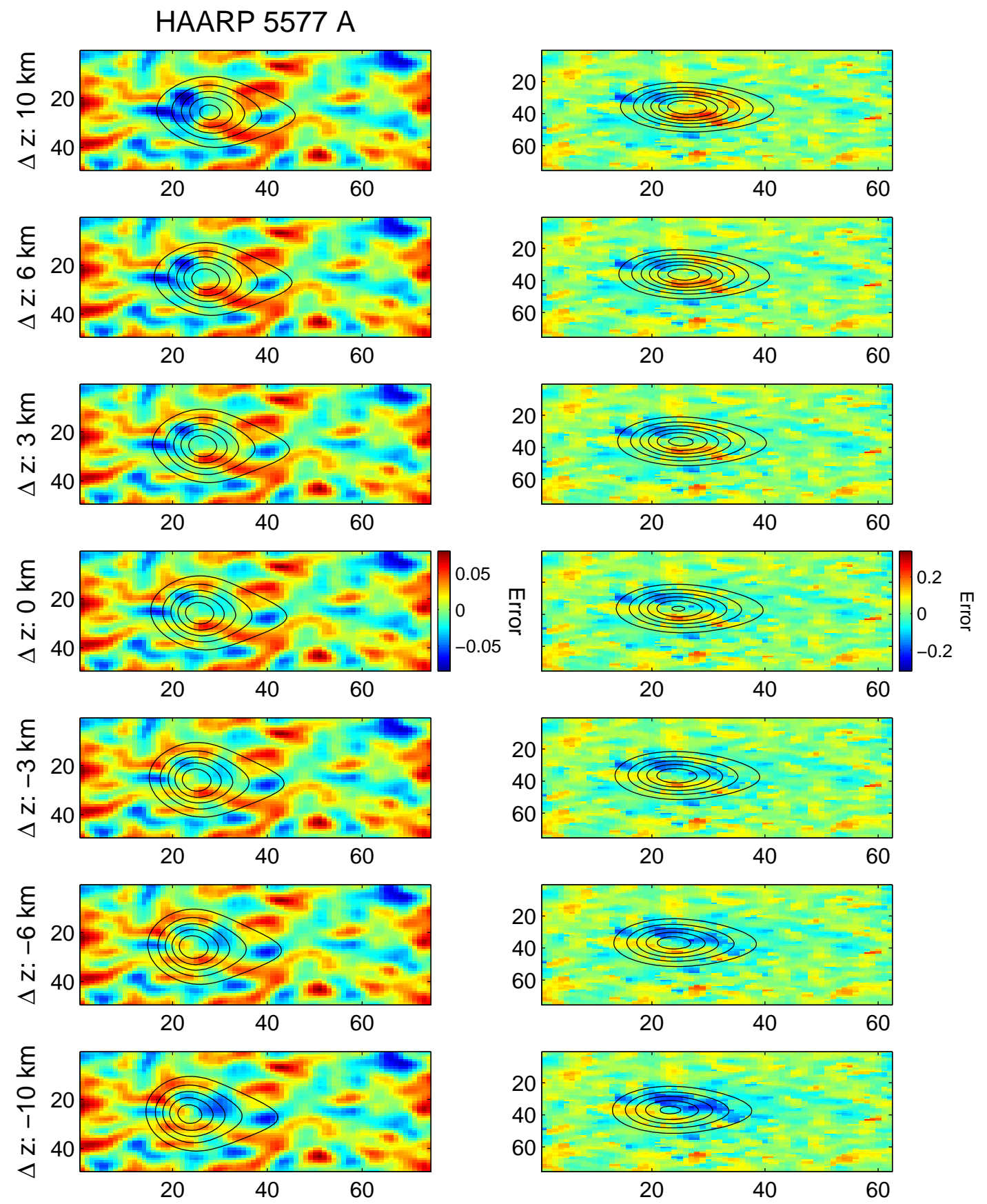

Fig. A1. HAARP image sections showing residuals between observed image and projection of three-dimensional models. In the left column for $5577 \AA$ where the "blob" is shifted in altitude one can see that there is systematically negative errors at pixel $(20,20)$ in the uppermost panel. This error decreases when the blob is lowered in altitude and for negative shifts there appears a region with negative errors around pixel $(30,20)$. For the best fit, in the middle panel there is no systematic errors. The same systematic pattern appears for the $6300 \AA$ residuals in the right column of panels.

HAARP and the corresponding projections start to appear, figure when the shift is $6 \mathrm{~km}$ up or down. This shows that the uncertainties is no worse than $\pm 3 \mathrm{~km}$ in altitude.

For a more formal estimate the accuracy of the retrieved parameters we have to, at least, determine how well we know the pixel line-of-sight directions, estimate the accuracy of the fit, and the parameter sensitivity to noise in the observations. The geometric camera calibration is done by adjusting relevant camera models so that agreement is obtained between stars identified in images and the corresponding position 


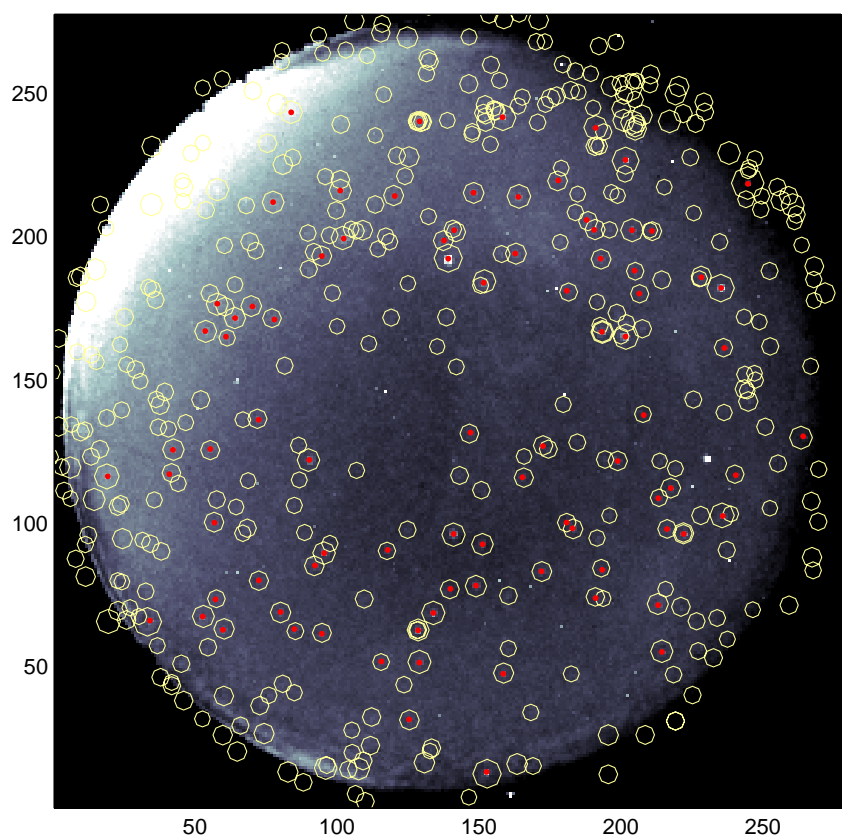

Fig. A2. Calibration image from the HAARP all-sky imager with overlayed stars, those used to determine camera rotation and intrinsic camera model parameters marked with red dots.

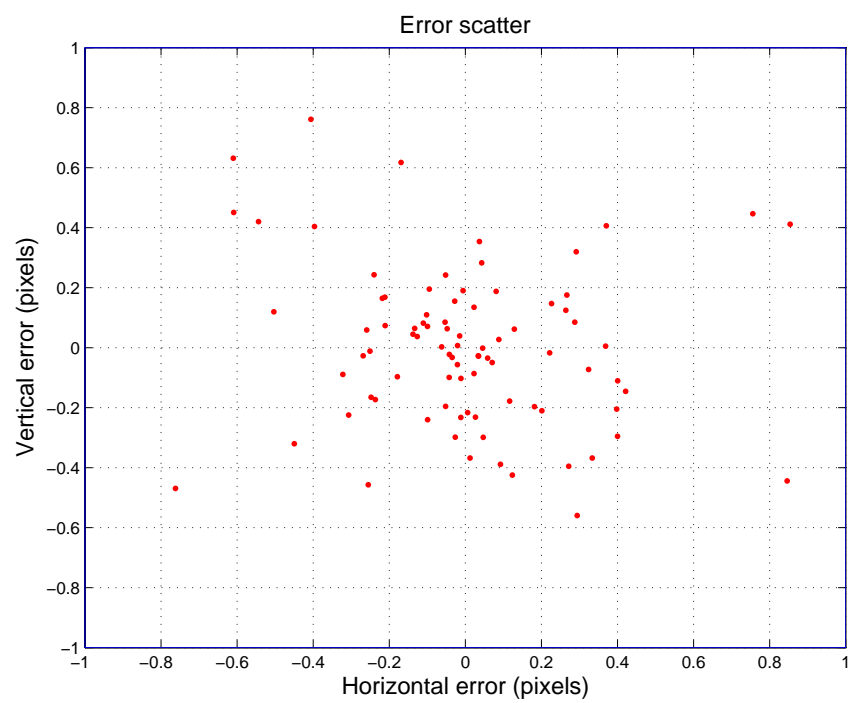

Fig. A3. Scatter plot of the difference between the HAARP image position of identified stars and the corresponding position calculated from the sky position of the stars and the camera parameters.

calculated from their sky position. To reduce the impact of noise and scintillation we typically identify $50-150$ stars in an image, preferably evenly distributed over the frame. After adjusting the camera model the fit should be equally good over the entire field-of-view, see Figs. A2, A4, A6. When the horizontal and vertical differences between the stars image and calculated positions are within $\pm 1 / 2$ pixel the most rig-

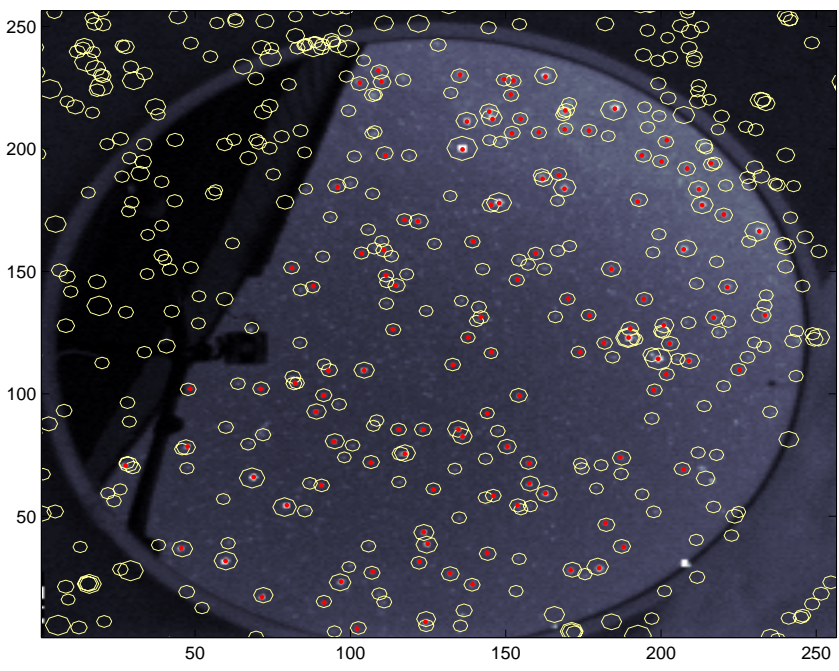

Fig. A4. Same as Fig. A2, but for the HAARPOON Apogee imager located at the HIPAS site, observation in $5577 \AA$.

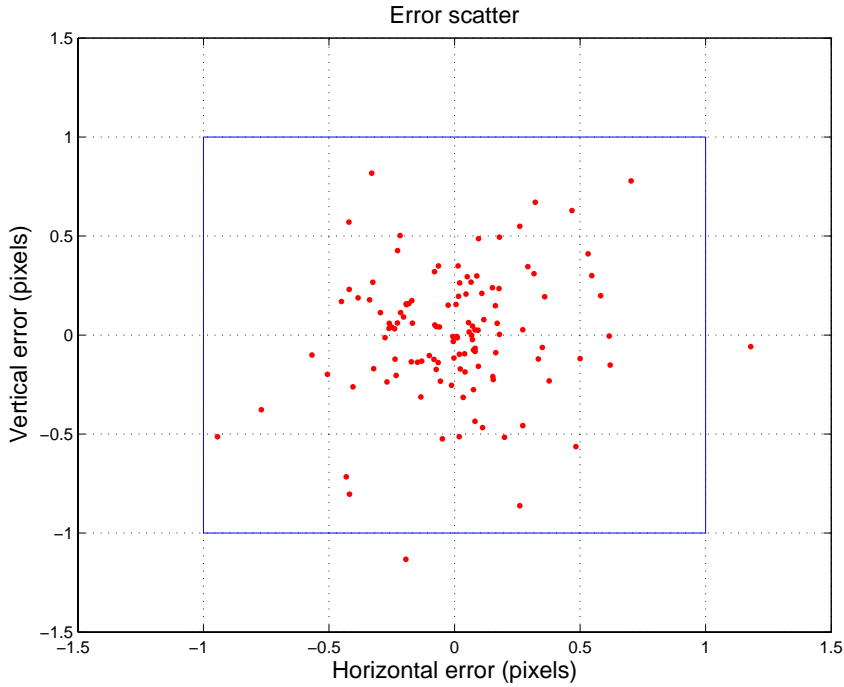

Fig. A5. Same as Fig. A3, but for the HAARPOON Apogee imager located at the HIPAS site.

orous requirement is met. As can be seen in Figs. A3, A5, A7 this has been achieved. The $1 \sigma$ spread of the scatter is within \pm 0.2 pixels for the stars in the HAARP imager, \pm 0.4 pixels for the $5577 \AA$ HIPAS imager and \pm 0.2 pixels for the $6300 \AA$ HIPAS imager. The line-of-sight angle between neighbouring pixels in the region of the enhanced spot is $0.5^{\circ}, 0.33^{\circ}$ $0.43^{\circ}$, respectively. Taking into account the distance to the region with enhanced emissions the pixel field-of-views for the three imagers covers areas of 3.2-by-3.2, 1.3-by-1.3 and 1.7 -by- $1.7 \mathrm{~km}$ in the region of interest, all with uncertainties of less than half that.

One way to estimate the noise sensitivity of the fitted parameters is to run Monte Carlo simulations of the imaging 


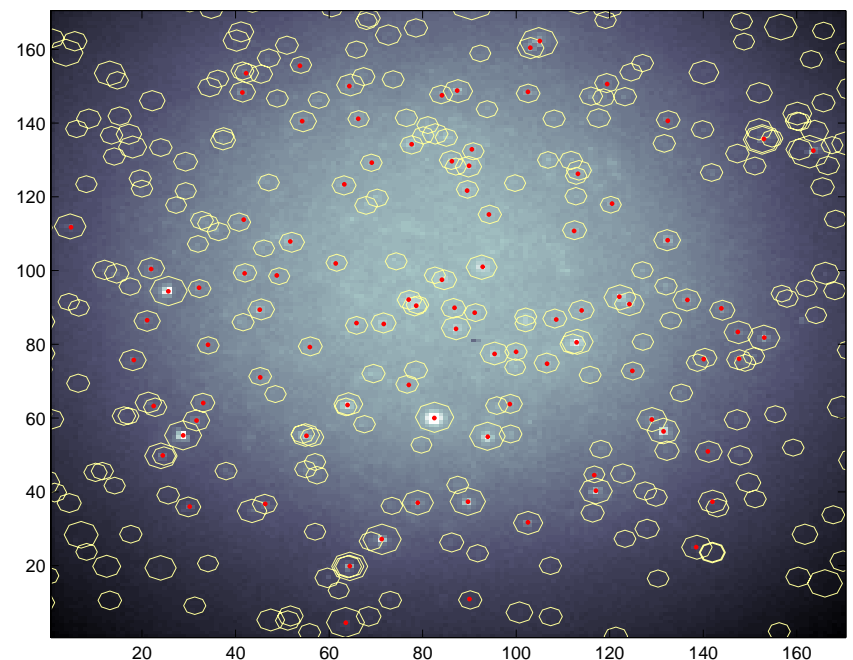

Fig. A6. Same as Fig. A2, but for the ST-9 imager located at the HIPAS site, observation in $6300 \AA$.

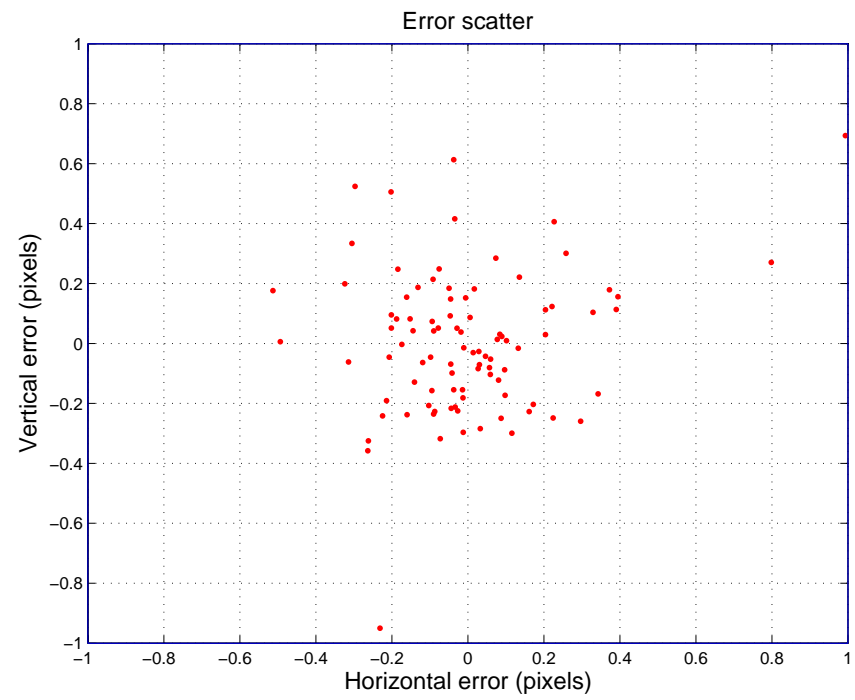

Fig. A7. Same as Fig. A3, but for the ST-9 imager located at the HIPAS site.

with relevant noise characteristics. The fitting procedure for our three-dimensional model is time-consuming, so in order to get sufficient statistics we chose to do the Monte Carlo modeling for a simplified two-dimensional model. This show that for comparable noise levels the standard deviations are: $1-2 \mathrm{~km}$ for the center of emission and the parameters $r_{x 0}, r_{y 0}, r_{z 0}$. For the parameters $\sigma_{i}$ the standard deviation is $3-5 \mathrm{~km}$, while the width, $\sigma_{\lambda}$, is more robust to noise with standard deviation of $1-3 \mathrm{~km}$. Since the diffusion coefficient, $D$ is not independent of the shape parameter $\gamma$ and the widths of the $\mathrm{O}\left({ }^{1} \mathrm{D}\right)$ excitation the current work cannot give reliable estimates of the neutral diffusion. This is a consequence of the fact that a true airglow emission distribution with unknown shape in an atmosphere with a diffusion coefficient $D$ might be best modeled with shape parameters $\gamma^{\prime}$ and a different diffusion coefficient $D^{\prime}$ (see also Gustavsson et al., 2001).

Acknowledgements. AFRL contributions were made under AFOSR task 2311AS. The CTIP simulation result have been provided by the Community Coordinated Modeling Center at Goddard Space Flight Center through their public Runs on Request system (http: //ccmc.gsfc.nasa.gov). The CCMC is a multi-agency partnership between NASA, AFMC, AFOSR, AFRL, AFWA, NOAA, NSF and ONR. The CTIP Model was developed by Timothy Fuller-Rowell et al. at the NOAA SEC.

Topical Editor K. Kauristie thanks D. Lummerzheim and another anonymous referee for their help in evaluating this paper.

\section{References}

Adeishvili, T. S., Gurevich, A. V., Liakhov, S. B., Managadze, G. G., Milikh, G. M., and Shliuger, I. S.: Ionospheric emission caused by an intense radio wave, Soviet J. Plasma Phys., 4, 1293-1301, 1978.

Aruliah, A. L., Griffin, E. M., Aylward, A. D., Ford, E. A. K., Kosch, M. J., Davis, C. J., Howells, V. S. C., Pryse, S. E., Middleton, H. R., and Jussila, J.: First direct evidence of meso-scale variability on ion-neutral dynamics using co-located tristatic FPIs and EISCAT radar in Northern Scandinavia, Ann. Geophys., 23, 147-162, 2005, http://www.ann-geophys.net/23/147/2005/.

Ashrafi, M., Kosch, M. J., Kaila, K., and Isham, B.: Spatiotemporal evolution of radio wave pump-induced ionospheric phenomena near the fourth electron gyroharmonic, J. Geophys. Res. (Space Physics), 112, 5314, doi:10.1029/2006JA011938, 2007.

Bernhardt, P. A., Tepley, C. A., and Duncan, L. M.: Airglow enhancements associated with plasma cavities formed during ionospheric heating experiments, J. Geophys. Res., 94, 9071-9092, 1989.

Bernhardt, P. A., Siefring, C. L., Rodriguez, P., Haas, D. G., Baumback, M. M., Romero, H. A., Solin, D. A., Djuth, F. T., Duncan, L. M., Hunton, D. E., Pollock, C. J., Sulzer, M. P., Tepley, C. A., Wagner, L. S., and Goldstein, J. A.: The Ionospheric Focused Heating experiment, J. Geophys. Res., 100, 17331-17346, doi: 10.1029/94JA01887, 1995.

Bernhardt, P. A., Wong, M., Huba, J. D., Fejer, B. G., Wagner, L. S., Goldstein, J. A., Selcher, C. A., Frolov, V. L., and Sergeev, E. N.: Optical remote sensing of the thermosphere with HF pumped artificial airglow, J. Geophys. Res., 105, $10657-10671,2000$.

Brändström, B. U. E.: The Auroral Large Imaging System - Design, operation and scientific results, $\mathrm{PhD}$ thesis, Swedish Institute of Space Physics, Kiruna, Sweden, Sci. Report 279, 2003.

Brändström, B. U. E., Leyser, T. B., Steen, Å., Rietveld, M. T., Gustavsson, B., Aso, T., and Ejiri, M.: Unambigous evidence of HF pump-enhanced airglow, Geophys. Res. Lett., 26, 35613564, 1999.

Carlson, H. C., Wickwar, V. B., and Mantas, G. P.: Observations of fluxes of suprathermal electrons accelerated by HF excited instabilities, J. Atmos. Terr. Phys., 44, 1089-1100, 1982.

Carlson Jr., H. C. and Mantas, G. P.: An experimental test of the ionosphere electron gas cooling rate by excitation of the fine 
structure of the ground state of atomic oxygen, J. Geophys. Res., 87, 4515-4524, 1982.

Closser, K. D., Pejaković, D. A., and Kalogerakis, K. S.: O(1D) Relaxation by $\mathrm{O}(3 \mathrm{P})$, AGU Fall Meeting Abstracts, p. A215, 2005.

Djuth, F. T., Bernhardt, P. A., Tepley, C. A., Gardner, J. A., Keley, M. C., Broadfoot, A. L., Kagan, L. M., Sulzer, M. P., Elder, J. H., Selcher, C., Isham, B., Brown, C., and Carlson, H. C.: Large Airglow Enhancements Produced via Wave-Plasma Interactions in Sporadic E, Geophys. Res. Lett., 26, 1557-1560, 1999.

Djuth, F. T., Pedersen, T. R., Gerken, E. A., Bernhardt, P. A., Selcher, C. A., Bristow, W. A., and Kosch, M. J.: Ionospheric Modification at Twice the Electron Cyclotron Frequency, Phys. Rev. Lett., 94, 125 001, doi:10.1103/PhysRevLett.94.125001, 2005.

Fejer, J. A. and Sulzer, M. P.: Observation of Suprathermal Electron Fluxes During Ionospheric Modification Experiments, J. Geophys. Res., 92, 3441-3444, 1987.

Fuller-Rowell, T. J., Rees, D., Quegan, S., Moffett, R. J., Codrescu, M. V., and Millward, G. H.: STEP Handbook of Ionospheric Models, chap. A coupled thermosphere-ionosphere model (CTIM), pp. 217-238, Utah State University, Logan, Utah, 1996.

Gondarenko, N. A., Ossakow, S. L., and Milikh, G. M.: Generation and evolution of density irregularities due to self-focusing in ionospheric modifications, J. Geophys. Res. (Space Physics), 110, A09304, doi:10.1029/2005JA011142, 2005.

Gustavsson, B. and Eliasson, B.: HF radio wave acceleration of ionospheric electrons: Analysis of HF-induced optical enhancements, J. Geophys. Res., 113, doi:10.1029/2007JA012913, 2008.

Gustavsson, B., Sergienko, T., Rietveld, M. T., Honary, F., Steen, Å., Brändström, B. U. E., Leyser, T. B., Aruliah, A. L., Aso, T., and Ejiri, M.: First Tomographic estimate of volume distribution of enhanced airglow emission caused by HF pumping, J. Geophys. Res., 106, 29 105-29 123, 2001.

Gustavsson, B., Brändström, B. U. E., Åke Steen, Sergienko, T., Leyser, T. B., Rietveld, M. T., Aso, T., and Ejiri, M.: Nearly simultaneous images of HF-pump enhanced airglow at $6300 \AA$ and $5577 \AA$, Geophys. Res. Lett., 29, 2220, doi:10.1029/2002GL015350, 2003.

Gustavsson, B., Sergienko, T., Kosch, M. J., Rietveld, M. T., Brändström, B. U. E., Leyser, T. B., Isham, B., Gallop, P., Aso, T., Ejiri, M., Steen, Å., Grydeland, T., la Hoz, C., Kaila, K., Jussila, J., and Holma, H.: The electron distribution during HF pumping, a picture painted with all colors, Ann. Geophys., 23, 1747-1754, 2005, http://www.ann-geophys.net/23/1747/2005/.

Gustavsson, B., Leyser, T. B., Kosch, M., Rietveld, M. T., Steen, Å., Brändström, B. U. E., and Aso, T.: Electron Gyroharmonic Effects in Ionization and Electron Acceleration during HighFrequency Pumping in the Ionosphere, Phys. Rev. Lett., 97, 195002, http://link.aps.org/abstract/PRL/v97/e195002, 2006.

Haslett, J. C. and Megill, L. R.: A model of the enhanced airglow excited by RF-radiation, Radio Sci., 9, 1005-1019, 1974.

Hecht, J. H., Strickland, D. J., and Conde, M. G.: The application of ground-based optical techniques for inferring electron energy deposition and composition change during auroral precipitation events, J. Atmos. Solar-Terr. Phys., 68, 1502-1519, doi:10.1016/ j.jastp.2005.06.022, 2006.

Hedin, A.: Extension of the MSIS Thermospheric Model into the
Middle and Lower Atmosphere, J. Geophys. Res., 96, 11591172, 1991.

Holma, H., Kaila, K. U., Kosch, M. J., and Rietveld, M. T.: Recognizing the blue emission in artificial aurora, Adv. Space Res., 38, 2653-2658, doi:10.1016/j.asr.2005.07.036, 2006.

Kalogerakis, K. S., Slanger, T. G., and Kendall, E. A.: $O\left({ }^{1} D\right)$ Decay in Ionospheric Modification Experiments, AGU Fall Meeting Abstracts, p. B1378, 2006.

Killeen, T. L. and Roble, R. G.: Thermosphere dynamics: contributions from the first 5 years of the Dynamics Explorer program. Rev. Geophys., 26, 329-367, 1988.

Kosch, M. J., Rietveld, M. T., Yeoman, T., Cierpka, K., and Hagfors, T.: The high-latitude artificial aurora of 21 February 1999: An analysis, Adv. Polar Upper Atmos. Res., 16, 1-12, 2002.

Kosch, M. J., Rietveld, M. T., Senior, A., McCrea, I. W., Kavanagh, A. J., Isham, B., and Honary, F.: Novel artificial optical annular structures in the high latitude ionosphere over EISCAT, Geophys. Res. Lett., 31, 12 805, doi:10.1029/2004GL019713, 2004.

Kosch, M. J., Pedersen, T., Mishin, E., Oyama, S., Hughes, J., Senior, A., Watkins, B., and Bristow, B.: Coordinated optical and radar observations of ionospheric pumping for a frequency pass through the second electron gyroharmonic at HAARP, J. Geophys. Res. (Space Physics), 112, 6325, doi: 10.1029/2006JA012146, 2007a.

Kosch, M. J., Pedersen, T., Mishin, E., Starks, M., Gerken-Kendall, E., Sentman, D., Oyama, S., and Watkins, B.: Temporal evolution of pump beam self-focusing at the High-Frequency Active Auroral Research Program, J. Geophys. Res. (Space Physics), 112, A08304, doi:10.1029/2007JA012264, 2007b.

Mantas, G. P. and Carlson, H. C.: Reinterpretation of the 6300$\AA ̊$ airglow enhancements observed in ionosphere heating experiments based on analysis of Platteville, Colorado, data, J. Geophys. Res., 101, 195-209, 1996.

Mantas, G. P., Carlson, H. C., and LaHoz, C. H.: Thermal Response of the F Region Ionosphere in Artificial Modification Experiments by HF Radio Waves, J. Geophys. Res., 86, 561-574, 1981.

Millward, G. H., Moffett, R. J., Quegan, S., and Fuller-Rowell, T. J.: STEP Handbook of Ionospheric Models, chap. A coupled thermosphere-ionosphere-plasmasphere model (CTIP), pp. 239280, Utah State University, Logan, Utah, 1996.

Mishin, E. V., Burke, W. J., and Pedersen, T.: On the onset of HFinduced airglow at HAARP, J. Geophys. Res. (Space Physics), 109, 2305, doi:10.1029/2003JA010205, 2004.

Mishin, E. V., Kosch, M. J., Pedersen, T. R., and Burke, W. J.: HFinduced airglow at magnetic zenith: Thermal and parametric instabilities near electron gyroharmonics, Geophys. Res. Lett., 32, L23106, doi:10.1029/2005GL023864, 2005.

Pedersen, T., Esposito, R., Kendall, E., Sentman, D., Kosch, M., Mishin, E., and Marshall, R.: Observations of artificial and natural optical emissions at the HAARP facility, Ann. Geophys., 26, 1089-1099, 2008, http://www.ann-geophys.net/26/1089/2008/.

Rietveld, M. T., Kohl, H., Kopka, H., and Stubbe, P.: Introduction to ionospheric heating at Troms $\varnothing-$ I. Experimental overview, J. Atmos. Terr. Phys., 55, 577-599, 1993.

Solomon, S. C., Hays, P. B., and Abreu, V. J.: The auroral $6300 \AA$ emisson: Observation and modelling, J. Geophys. Res., 93, 9867-9882, 1988. 